\title{
Robust non-linear control of a hybrid water pumping system based on induction motor
}

\author{
Zakaria Massaq, Abdelouahed Abounada, Mohamed Ramzi \\ Department of Electrical Engineering, LACEM, Faculty of Sciences and Technology, Sultan Moulay Slimane University, \\ Beni-Mellal, Morocco
}

\begin{tabular}{|c|c|}
\hline Article Info & ABSTRACT \\
\hline Article history: & This contribution presents a non-linear control of a hybrid pumping system \\
\hline Received Feb 22, 2020 & $\begin{array}{l}\text { supplied with a photovoltaic generator and a battery. This system is } \\
\text { employed for delivering a continuous volume of water whatever the climatic }\end{array}$ \\
\hline Revised Apr 26, 2020 & conditions. In the DC side, a boost converter is controlled with the indirect \\
\hline Accepted May 19, 2020 & $\begin{array}{l}\text { double integral sliding mode controller (DISMC) for maximum power point } \\
\text { tracking (MPPT). The DISMC is suitable for MPPT because it gives a fast }\end{array}$ \\
\hline Keywords: & $\begin{array}{l}\text { response and reduces the amplitude of power oscillations. Then, a } \\
\text { bidirectional buck-boost converter is adopted to ensure the energy }\end{array}$ \\
\hline Bid & management between the battery and the DC-bus, and this converter is \\
\hline Hybrid water pumping system & $\begin{array}{l}\text { controlled with integral sliding mode control (ISMC) theory. The non-linear } \\
\text { predictive control (NPC) is chosen to drive an induction motor (IM), the }\end{array}$ \\
\hline Integral sliding mode controller & NPC is known by its fast dynamic and high capacity to reject disturbances. \\
\hline MPPT perturb and Observe & The hybrid system is modelled in MATLAB/Simulink software. During \\
\hline Non-linear predictive control & $\begin{array}{l}\text { simulations, the DISMC-MPPT is compared with other techniques such as } \\
\text { sliding mode controller (SMC) MPPT and integral SMC MPPT, the DISMC } \\
\text { provides the best tracking performances under different irradiances. } \\
\text { Moreover, the designed controller for the bidirectional converter regulates } \\
\text { the DC-link voltage with better performances than the classical PI controller. } \\
\text { Lastly, the NPC regulates the speed of the IM with high robustness. }\end{array}$ \\
\hline
\end{tabular}

This is an open access article under the CC BY-SA license.

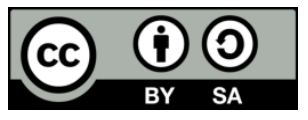

\section{Corresponding Author:}

Zakaria Massaq,

Departement of Electrical Engineering,

Faculty of Sciences and Technology, Sultan Moulay Slimane University

B.P: 523 Beni-Mellal, Morroco.

Email: zakaria.massaq@gmail.com

\section{INTRODUCTION}

The sliding mode control (SMC) is suitable for fast maximum power point tracking (MPPT) because it is known by stability, fast-response and non-sensitivity to parameter variation [1]. The conventional hysteresis-modulation (HM) based SMC suffers from variable switching frequency and from the chattering phenomenon due to the high switching frequency operation. These drawbacks motivated the researchers to design an indirect SMC based on the pulse width modulation (PWM) technique. The conventional SMC with PWM exhibits an unwanted steady-state error and slow response [2], to improve the response of indirect SMC an integral term is added to the existing sliding surface to constitute the integral sliding mode controller (ISMC) $[3,4]$. However, the construction of the indirect form of the ISMC derivates the state variables of the switching surface $(\dot{S}=0)$, thus, the variable $\int x_{i} d t$ disappears from the equivalent control term $\mathrm{u}_{\mathrm{eq}}$, and the correction of steady-state error is deteriorated $[5,6]$. Therefore, an integral term is added for the second time $\left.\int\left(\int x_{i} d t\right)\right) d t$ to nullify the steady-state error introduced by the indirect ISMC, this new technique is called 
PWM based double integral SMC (DISMC) [2]. The DISMC shows a fast response and reduces the steadystate error [4]. The bidirectional (BDC) DC-DC converter is the key factor of energy management between PV source, battery, and different loads [7, 8]. However, the use of two PI controllers to control the bidirectional converter does not guarantee good performances when the system operates outside of the operating point $[9,10]$. For that reason, the features of the ISMC theory are exploited to control the bidirectional converter in this paper.

The discovering of field-oriented control (FOC) in 1972 has revolutionized the control theory of the induction motor (IM) [11-13]. However, the FOC technique uses coordinate transformation which makes it complex to implement, in addition, it is sensitive to internal parameters variation of the machine [14, 15]. To minimize the complexity of FOC and improving its dynamic new control techniques have been founded, namely sliding mode control (SMC), and direct torque control (DTC) [16, 17]. The IM model is non-linear in nature, furthermore, the IM is applied to external disturbances (load torque) and to internal parameter variations. Therefore, the robust non-linear predictive control (NPC) is applied to control the IM in this work. The NPC uses high order calculations to optimize a cost function; the complexity of calculation could be reduced using the Taylor series expansion of the output's variables $[18,19]$.

This contribution proposes a high-performance control scheme for a hybrid water pumping system. Section 2 presents a brief description of the different stages of the pumping system. Section 3 presents the different control strategies for the pumping system. First, a cascaded controller based on DISMC is presented for MPPT. Afterward, two other controllers based on ISMC theory are designed to control the bidirectional flow of the energy. Finally, the control scheme for the IM based on NPC is explained. Simulation results and analysis are reported to section 4 , followed by general conclusions.

\section{CIRCUIT CONFIGURATION}

A hybrid water pumping system is presented in Figure 1. The overall system comprises a PV array as a principal source of energy and a battery pack considered as a second power source. The system includes static DC-DC converters such as a unidirectional boost converter used for MPPT and a bidirectional buckboost converter which ensures the bidirectional flow of the energy between the DC-bus and the battery. Finally, a two-level inverter controls an induction motor with a centrifugal pump.

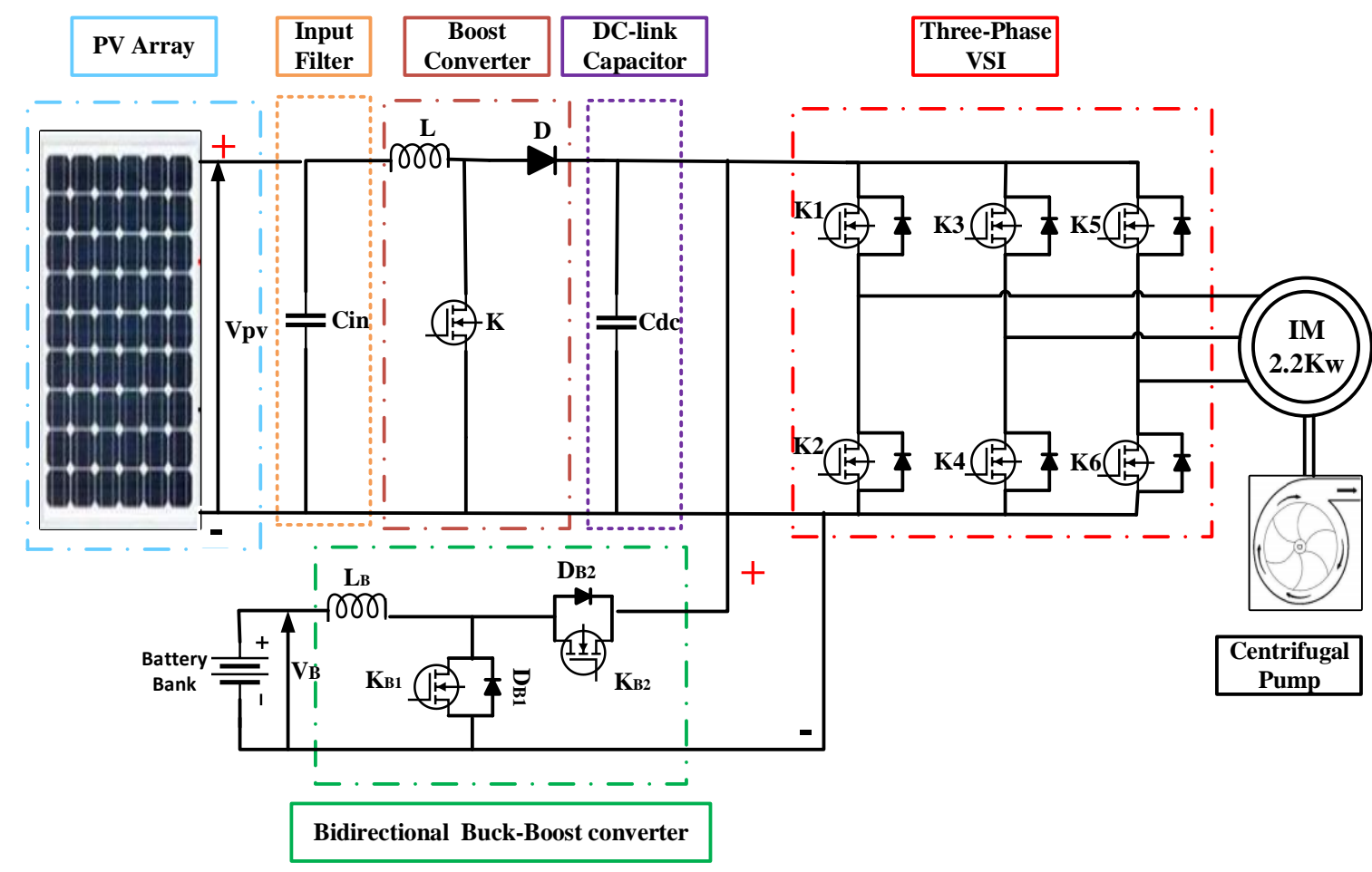

Figure 1. Block diagram of the hybrid system 


\section{CONTROL STRATEGIES}

Diverse controllers are proposed to control the hybrid system, and are listed as follows:

- A DISMC based on PWM is designed to track the maximum power point (MPP) with high efficiency.

- The bidirectional buck-boost converter is controlled with the ISMC theory to regulate the DC-bus voltage.

- Control of the induction motor with the generalized predictive controller.

\subsection{Maximum power point tracking control}

Figure 2 shows the MPPT control scheme, in which a perturb and observe $(\mathrm{P} \& \mathrm{O})$ algorithm generates the reference voltage $\mathrm{V}_{\mathrm{pv}}{ }^{*}$. Then, a DISMC is used to force the state trajectory of the boost converter to follow the reference voltage given by the $\mathrm{P} \& \mathrm{O}$ algorithm.

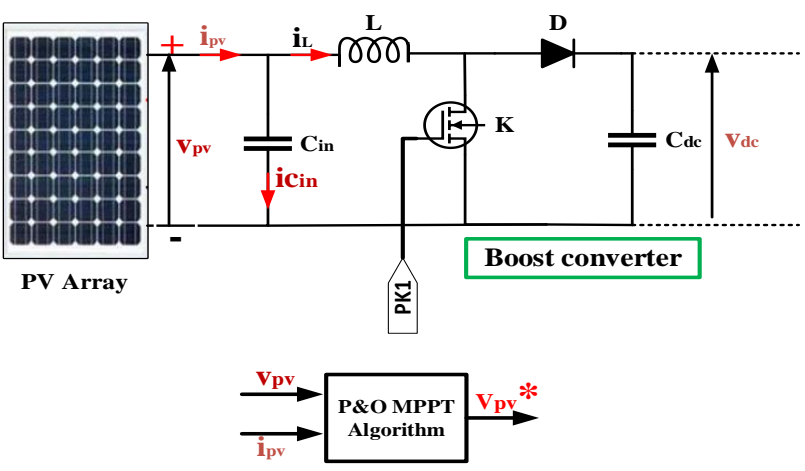

Figure 2. DISMC- MPPT algorithm control scheme

\subsubsection{Design of a double integral sliding mode controller for MPPT}

Considering that the boost converter operates in continuous conduction mode (CCM), The average state-space model of the boost converter is presented in term of the switching signal $\mathrm{u}_{1}$ as,

$$
\dot{x_{1}}=f\left(x_{1}\right)+g\left(x_{1}\right) \mathrm{u}_{1}
$$

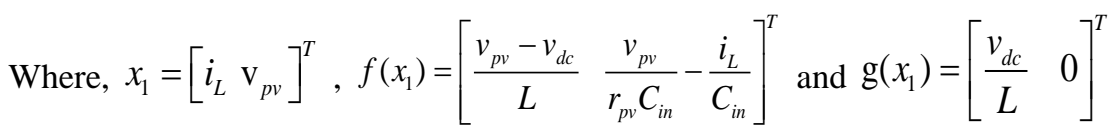

Where, $\mathrm{r}_{\mathrm{pv}}$ is the dynamic resistance of the PV array. The general control law to control the voltage $\mathrm{v}_{\mathrm{pv}}$ is:

$$
u_{1}=\left\{\begin{array}{lll}
0 & \text { when } & \mathrm{S}_{1} \succ 0 \\
1 & \text { when } & \mathrm{S}_{1} \prec 0
\end{array}\right.
$$

Where $S_{1}$ is the switching surface, which is expressed as,

$$
S_{1}=a_{1} e_{1}+a_{2} e_{2}+a_{3} e_{3}+a_{4} e_{4}
$$

The terms $a_{1}-a_{4}$ denote the sliding surface parameters, and $e_{1}-e_{4}$ are the error signals.

$$
\left\{\begin{array}{l}
\mathrm{e}_{1}=i_{L}^{*}-i_{L} \quad / \mathrm{i}_{L}^{*}=A\left(\mathrm{~V}_{p v}^{*}-\beta v_{p v}\right) \\
\mathrm{e}_{2}=V_{p v}^{*}-\beta v_{p v} \\
\mathrm{e}_{3}=\int\left(\mathrm{V}_{p v}^{*}-\beta v_{p v}\right) d t \\
\mathrm{e}_{4}=\int\left[\int\left(V_{p v}^{*}-\beta v_{p v}\right) \mathrm{dt}\right] d t
\end{array}\right.
$$


Where, $\mathrm{A}$ is the amplified gain of the voltage error. The application of the indirect SMC is achieved through the computation of the equivalent control $\mathrm{u}_{1 \mathrm{eq}}$. This can be derived from the invariance condition, $\dot{S}_{1}=0$,

$$
\begin{aligned}
& \dot{S}_{1}=a_{1} \dot{e}_{1}+a_{2} \dot{e}_{2}+a_{3} \dot{e}_{3}+a_{4} \dot{e}_{4}=0 \\
& \text { Then, } u_{1 e q}=1-A_{1} \frac{i c_{i n}}{v_{d c}}-\frac{v_{p v}}{v_{d c}}+A_{2} \frac{e_{2}}{v_{d c}}+A_{3} \frac{e_{3}}{v_{d c}} \\
& A_{1}=\left(\frac{A \beta L}{C_{i n}}+\frac{a_{2} \beta L}{a_{1} C_{i n}}\right), A_{2}=\frac{a_{3} L}{a_{1}} \text { and } A_{3}=\frac{a_{4} L}{a_{1}}
\end{aligned}
$$

With,

$\mathrm{A}_{1}, \mathrm{~A}_{2}$, and $\mathrm{A}_{3}$ parameters are empirically determined according to the existence and stability criterions [2, 4]. The control law of the indirect sliding mode control is derived using PWM technique, comparing control signal $\mathrm{v}_{\text {control1 }}$ with a ramp signal $\mathrm{v}_{\text {rampl }}$.

$$
\left\{\begin{array}{l}
v_{\text {control } 1}=\left(\mathrm{v}_{d c}-v_{p v}\right)-A_{1} i c_{i n}+A_{2} e_{2}+A_{3} e_{3} \\
v_{\text {ramp } 1}=\beta v_{p v}
\end{array}\right.
$$

\subsection{The control strategy of the bidirectional converter}

The BDC is considered as the intermediate link between the battery and the DC bus. If the DC-link voltage is greater than the reference voltage $\mathrm{v}_{\mathrm{dc}}>\mathrm{V}_{\mathrm{dc}}{ }^{*}$, the BDC operates in buck mode to store the excess of energy in the battery. On the other hand, if $\mathrm{v}_{\mathrm{dc}}<\mathrm{V}_{\mathrm{dc}}{ }^{*}$ the battery discharges to inject the required current into the DC-bus, in this case, the BDC works in boost mode [20,21]. The direction of the current is reversed from one mode to another. To control the BDC in both modes of operation two strategies of control are proposed as presented in Figure 3.

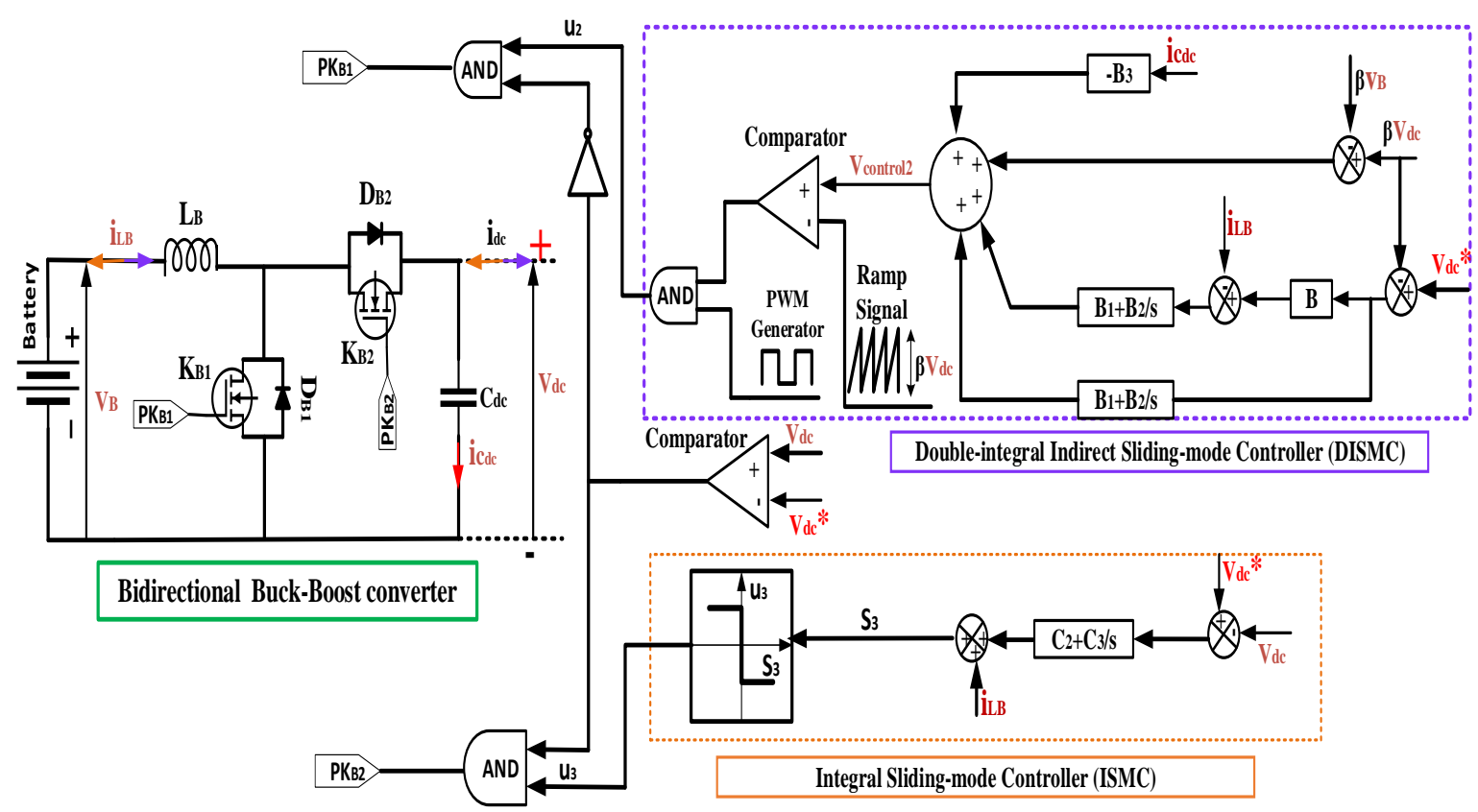

Figure 3. The proposed control scheme for the bidirectional converter

\subsubsection{Design of a double integral sliding mode controller for the boost converter mode}

Considering that the boost converter operates in CCM, and the chosen state variables are the inductor current $i_{L B}$ and the DC-link voltage $v_{d c}$. The dynamic of the boost converter is described with the differential equations in (8), where $\mathrm{u}_{2}$ refers to the state of the switch $\mathrm{K}_{\mathrm{B} 1}$. 


$$
\dot{x}_{2}=f\left(x_{2}\right)+g\left(x_{2}\right) \mathrm{u}_{2}
$$

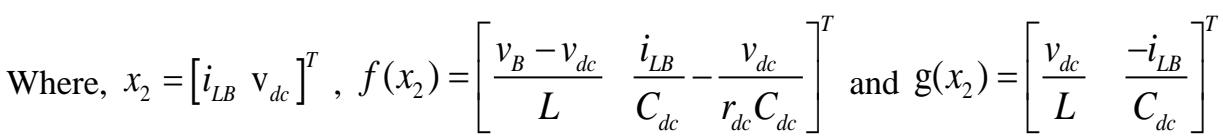

$\mathrm{r}_{\mathrm{dc}}$ is the dynamic resistance of the DC bus.

The sliding surface is formed with the state variables errors (9).

$$
S_{2}=b_{1} e_{1}+b_{2} e_{2}+b_{3} e_{3}+b_{4} e_{4}
$$

where $e_{1}-e_{4}$ are the current and voltage errors, and B is the gain which amplifies the voltage error.

$$
\left\{\begin{array}{l}
\mathrm{e}_{1}=i_{L B}^{*}-i_{L B} \quad / \mathrm{i}_{L B}^{*}=B\left(V_{d c}^{*}-\beta v_{d c}\right) \\
\mathrm{e}_{2}=V_{d c}^{*}-\beta v_{d c} \\
\mathrm{e}_{3}=\int\left(\mathrm{e}_{1}+\mathrm{e}_{2}\right) d t \\
\mathrm{e}_{4}=\int\left[\int\left(\mathrm{e}_{1}+\mathrm{e}_{2}\right) \mathrm{dt}\right] d t
\end{array}\right.
$$

Substituting the dynamic of the step-up converter in the derivative of the sliding surface $\left(\dot{S}_{2}=0\right)$ gives,

$$
\dot{S}_{2}=b_{1}\left(\frac{v_{d c}-v_{B}-u_{2} v_{d c}}{L_{B}}-B \beta \frac{i c_{d c}}{C_{d c}}\right)-b_{2} \beta \frac{i c_{d c}}{C_{d c}}+b_{3}\left(e_{1}+e_{2}\right)+b_{4} \int\left(e_{1}+e_{2}\right) d t
$$

The equivalent control signal $\mathrm{u}_{2 \mathrm{eq}}$ of the boost converter is obtained by solving the following equation $\dot{S}_{2}=0$,

$$
u_{e q 2}=1-\frac{\beta L_{B}}{C_{d c} v_{d c}}\left(\mathrm{~B}+\frac{b_{2}}{b_{1}}\right) \mathrm{i} c_{d c}-\frac{v_{B}}{v_{d c}}+\frac{b_{3} L_{B}}{b_{1} v_{d c}}\left(V_{d c}^{*}-\beta v_{d c}\right)+\frac{b_{3} L_{B}}{b_{1} v_{d c}}\left[\mathrm{~B}\left(V_{d c}^{*}-\beta v_{d c}\right)-i_{L B}\right]+\frac{b_{4} L_{B}}{b_{1} v_{d c}} \int\left(\mathrm{V}_{d c}^{*}-\beta v_{d c}\right) d t+\frac{b_{4} L_{B}}{b_{1} v_{d c}} \int\left[\mathrm{B}\left(V_{d c}^{*}-\beta v_{d c}\right)-i_{L B}\right] d t
$$

The control law is derived using the PWM technique, comparing the voltage control signal $\mathrm{v}_{\text {control2 }}$ with a ramp signal $v_{\text {ramp2. }}$.

$$
\left\{\begin{array}{l}
v_{\text {control2 } 2}=\mathrm{B}_{1}\left(V_{d c}^{*}-\beta v_{d c}\right)+B_{1}\left[\mathrm{~B}\left(V_{d c}^{*}-\beta v_{d c}\right)-i_{L B}\right]+B_{2} \int\left(V_{d c}^{*}-\beta v_{d c}\right) d t+B_{2} \int\left[\mathrm{B}\left(V_{d c}^{*}-\beta v_{d c}\right)-i_{L B}\right] d t-B_{3} i c_{d c}+G_{s}\left(\mathrm{v}_{d c}-v_{B}\right) \\
v_{\text {ramp } 2}=G_{s} v_{d c}
\end{array}\right.
$$

Here, the factor $G_{s}=\beta\left(0<G_{s}<1\right)$ is used to downscale voltage magnitude to a practical level. $B_{1}-B_{3}$ are constant parameters determined according to reachability and stability conditions [5, 22]. The duty ratio is multiplied with a signal of the pulse generator to ensure that the duty ratio is always less than 1 . Figure 3 illustrates the control scheme of the implemented DISMC-PWM.

$$
B_{1}=G_{s} \frac{b_{3}}{b_{1}} L_{B}, B_{2}=G_{s} \frac{b_{4}}{b_{1}} L_{B} \text { and } B_{3}=G_{s} \frac{\beta L_{B}}{C_{d c}}\left(\mathrm{~B}+\frac{b_{2}}{b_{1}}\right)
$$

\subsubsection{Design of Integral sliding mode controller for the buck converter mode}

Considering that the buck converter operates in CCM, and the chosen state variables are the inductor current $\mathrm{I}_{\mathrm{LB}}$ and ${ }^{\text {the }} \mathrm{DC}$-link voltage $\mathrm{V}_{\mathrm{dc}}$. The dynamic of the buck converter is described with the differential equations (14), where $\mathrm{u}_{3}$ refers to the state of the switch $\mathrm{K}_{\mathrm{B} 2}$.

$$
\dot{x}_{3}=f\left(x_{3}\right)+g\left(x_{3}\right) \mathrm{u}_{3}
$$


where, $x_{3}=\left[\begin{array}{ll}i_{L B} & \mathrm{v}_{d c}\end{array}\right]^{T}, f\left(x_{3}\right)=\left[\begin{array}{ll}\frac{-v_{B}}{L_{B}} & \frac{i_{d c}}{C_{d c}}\end{array}\right]^{T}$ and $\mathrm{g}\left(x_{3}\right)=\left[\begin{array}{ll}\frac{v_{d c}}{L_{B}} & \frac{-i_{L B}}{C_{d c}}\end{array}\right]^{T}$

the switching surface $S_{3}$ is formed with the DC-link voltage error $\left(e_{1}\right)$, the integration of this error $\left(e_{2}\right)$ and the inductor current $i_{\text {LB }}$. The sliding surface $S_{3}$ is expressed in (15),

$$
S_{3}=c_{1} e_{1}+c_{2} e_{2}+i_{L B}
$$

where, $c_{1}$ and $c_{2}$ are the sliding surface parameters determined according to reachability condition $[9,25]$, the errors are given by,

$$
\left\{\begin{array}{l}
\mathrm{e}_{1}=V_{d c}^{*}-v_{d c} \\
\mathrm{e}_{2}=\int\left(V_{d c}^{*}-v_{d c}\right) \mathrm{dt}
\end{array}\right.
$$

the control discrete function of the buck converter is concluded from the transversality condition [25].

$$
u_{3}=\left\{\begin{array}{lll}
1 & \text { when } & \mathrm{S}_{3}<0 \\
0 & \text { when } & \mathrm{S}_{3}>0
\end{array}\right.
$$

the derivative of the switching surface is given in equation (18),

$$
\dot{S}_{3}=-c_{1}\left(\frac{i_{d c}}{C_{d c}}-\frac{u_{3} i_{L B}}{C_{d c}}\right)+c_{2} e_{1}+\left(\frac{u_{3} v_{d c}}{L_{B}}-\frac{v_{B}}{L_{B}}\right)
$$

solving the equation $\left(\dot{S}_{3}=0\right)$, the control signal would be:

$$
u_{3 e q}=\frac{\frac{c_{1} i_{d c}}{C_{d c}}+\frac{v_{B}}{L_{B}}-c_{2}\left(V_{d c}^{*}-v_{d c}\right)}{\frac{c_{1} i_{L B}}{C_{d c}}+\frac{v_{d c}}{L_{B}}}
$$

\subsection{Non-linear predictive control of induction motor}

Figure 4 presents the non-linear predictive control of the induction motor. The mathematical model of the IM is presented in the two-dimensional stator reference frame $(\alpha-\beta)[26]$ is:

$$
\dot{x}=f(x)+g(x) \mathrm{u}(\mathrm{t})
$$

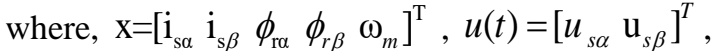

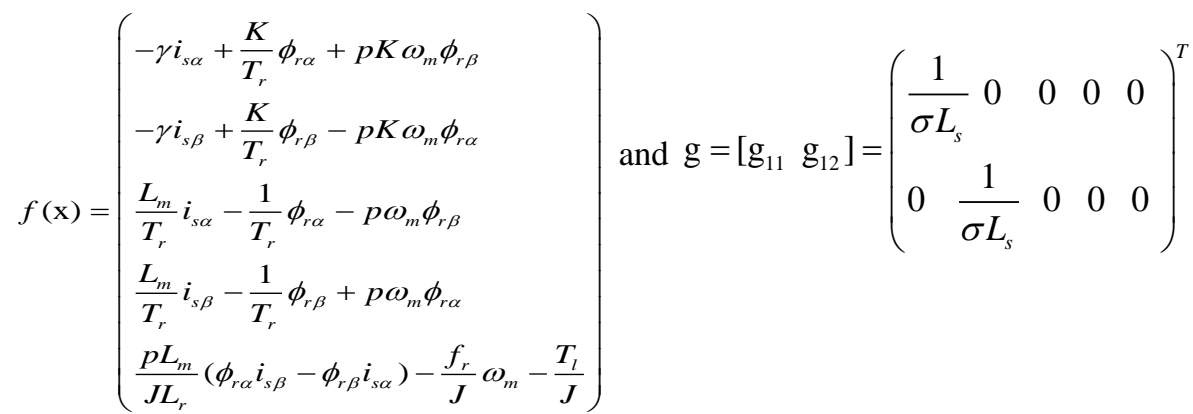


where, $\mathrm{u}_{\mathrm{s} \alpha}, \mathrm{u}_{\mathrm{s} \beta}, \mathrm{i}_{\mathrm{s} \alpha}, \mathrm{i}_{\mathrm{s} \beta}$ are the stator voltages and the stator currents, respectively, and $\phi_{\mathrm{r} \alpha}, \phi_{\mathrm{r} \beta}$ are rotor fluxes. The constant parameters of the model are defined by,

$$
\sigma=1-\left(\frac{\mathrm{L}_{\mathrm{m}}^{2}}{\mathrm{~L}_{\mathrm{s}} \mathrm{L}_{\mathrm{r}}}\right) ; K=\frac{L_{m}}{\sigma L_{s} L_{r}} ; \gamma=\frac{1}{\sigma L_{s}}\left(R_{s}+R_{r} \frac{L_{m}^{2}}{L_{r}^{2}}\right)
$$

where, $\mathrm{L}_{\mathrm{s}}, \mathrm{L}_{\mathrm{r}}$ are stator and rotor inductances, and $\mathrm{L}_{\mathrm{m}}$ is the mutual inductance, $\mathrm{R}_{\mathrm{s}}, \mathrm{R}_{\mathrm{r}}$ are stator and rotor resistances, and $T_{r}=L_{r} / R_{r}$ is rotor time constant, $p$ number of poles pair, $T_{1}$ load torque, $J$ inertia coefficient, $f_{r}$ friction coefficient. The square of rotor flux and the speed are two chosen output to be regulated,

$$
y=h(x)=\left(\begin{array}{ll}
\mathrm{y}_{1} & \mathrm{y}_{2}
\end{array}\right)^{T}=\left(\mathrm{h}_{1}(x) \mathrm{h}_{2}(\mathrm{x})\right)^{T}=\left(\begin{array}{ll}
\omega_{m} & \phi_{r}{ }^{2}=\phi_{r \alpha}{ }^{2}+\phi_{r \beta}{ }^{2}
\end{array}\right)^{T}
$$

the controlled variables can be expressed with Lie derivatives as,

$$
Y(t)=\left(\begin{array}{l}
\mathrm{y}(\mathrm{t}) \\
\dot{y}(\mathrm{t}) \\
\ddot{y}(\mathrm{t})
\end{array}\right)=\left(\begin{array}{c}
\mathrm{h}(x) \\
\mathrm{L}_{f} \mathrm{~h}(\mathrm{x}) \\
\mathrm{L}_{f}^{2} h(x)
\end{array}\right)+\left(\begin{array}{c}
0_{2 \times 1} \\
0_{2 \times 1} \\
G_{1}(x) u(t)
\end{array}\right)
$$

where, $G_{1}(x)=\left(\begin{array}{cc}\mathrm{L}_{g_{11}} \mathrm{~L}_{f} \mathrm{~h}_{1}(x) & \mathrm{L}_{g_{12}} \mathrm{~L}_{f} \mathrm{~h}_{1}(x) \\ \mathrm{L}_{g_{11}} \mathrm{~L}_{f} \mathrm{~h}_{2}(x) & \mathrm{L}_{g_{12}} \mathrm{~L}_{f} \mathrm{~h}_{2}(x)\end{array}\right), \mathrm{L}_{f}^{i} \mathrm{~h}(\mathrm{x})=\left[\mathrm{L}_{f}^{i} \mathrm{~h}_{1}(\mathrm{x}) \mathrm{L}_{f}^{i} \mathrm{~h}_{2}(\mathrm{x})\right]^{\mathrm{T}}, \quad 0 \leq \mathrm{i} \leq 2$

where, $L_{f} h_{j}(x)$ operator is Lie derivative notation of the function $\mathrm{h}_{\mathrm{j}}$ with the respect to $\mathrm{f}(\mathrm{x})$.

The basic idea behind the predictive control consists of the construction of a control law $u(t)$ able to force the system trajectory to follow the desired trajectory in a future horizon $\left(t+\tau_{r}\right)$. The control law is obtained through the optimization of the cost function expressed as,

$$
J=\frac{1}{2} \int_{0}^{\tau_{r}}\left(y(t+\tau)-\mathrm{y}_{r}(\mathrm{t}+\tau)\right)^{T}\left(\mathrm{y}(\mathrm{t}+\tau)-\mathrm{y}_{r}(\mathrm{t}+\tau)\right) \mathrm{d} \tau
$$

using Taylor series expansion of the outputs and of the reference outputs the cost function can be rewritten as $[15,18]$ :

$$
J=\left(\mathrm{Y}(t)-Y_{r}(\mathrm{t})\right)^{T} \bar{\Pi}\left(\mathrm{Y}(\mathrm{t})-Y_{r}(\mathrm{t})\right)
$$

where, $Y_{r}(t)=\left(\mathrm{y}_{r}(\mathrm{t}) \dot{y}_{r}(\mathrm{t}) \ddot{y}_{r}(\mathrm{t})\right)^{T}, y_{r}=\left(\omega_{m}^{*} \phi_{r}^{2^{*}}\right)^{T} \quad$ and

$$
\bar{\Pi}=\int_{0}^{\tau_{r}} \overline{\mathrm{T}}(\tau)^{T} \overline{\mathrm{T}}(\tau) d \tau=\left(\begin{array}{cc:c}
\tau_{\mathrm{r}} \mathrm{I}_{2 \times 2} & \frac{\tau_{\mathrm{r}}{ }^{2}}{2} \mathrm{I}_{2 \times 2} & \frac{\tau_{\mathrm{r}}{ }^{3}}{6} \mathrm{I}_{2 \times 2} \\
\frac{\tau_{\mathrm{r}}{ }^{2}}{2} \mathrm{I}_{2 \times 2} & \frac{\tau_{\mathrm{r}}{ }^{3}}{3} \mathrm{I}_{2 \times 2} & \frac{\tau_{\mathrm{r}}{ }^{4}}{8} \mathrm{I}_{2 \times 2} \\
\hdashline \frac{\tau_{\mathrm{r}}{ }^{3}}{6} \mathrm{I}_{2 \times 2} & \frac{\tau_{\mathrm{r}}{ }^{4}}{8} \mathrm{I}_{2 \times 2} & \frac{\tau_{\mathrm{r}}{ }^{5}}{20} \mathrm{I}_{2 \times 2}
\end{array}\right)=\left(\begin{array}{c:c}
\overline{\Pi_{1}} & \bar{\Pi}_{2} \\
\hdashline \bar{\Pi}_{2}{ }^{T} & \bar{\Pi}_{3}
\end{array}\right)
$$

the optimal control law is deduced by setting the following condition,

$$
\frac{\partial J}{\partial u}=0 \Leftrightarrow \mathrm{G}_{1}(\mathrm{x})^{T}\left[{\overline{\Pi_{2}}}^{T} \bar{\Pi}_{3}\right] M+\mathrm{G}_{1}(\mathrm{x})^{T} \bar{\Pi}_{3} \mathrm{G}_{1}(\mathrm{x}) u(t)=0
$$

finally, the control law $\mathrm{u}(\mathrm{t})$ is obtained by, 


$$
u(t)=-G_{1}(x)^{-1}\left[{\overline{\Pi_{3}}}^{-1}{\overline{\Pi_{2}}}^{T} \mathrm{I}_{2 \times 2}\right] M
$$

the conditions $\left\{\left\{\phi_{r \alpha}^{2}+\phi_{r \beta}^{2} \neq 0\right\}\right.$ and $\left.\left\{\phi_{r \alpha}, \phi_{r \beta}\right\} \neq 0\right\}$ should be fulfilled to inverse the matrix $\mathrm{G}_{1}(\mathrm{x})$ [15].

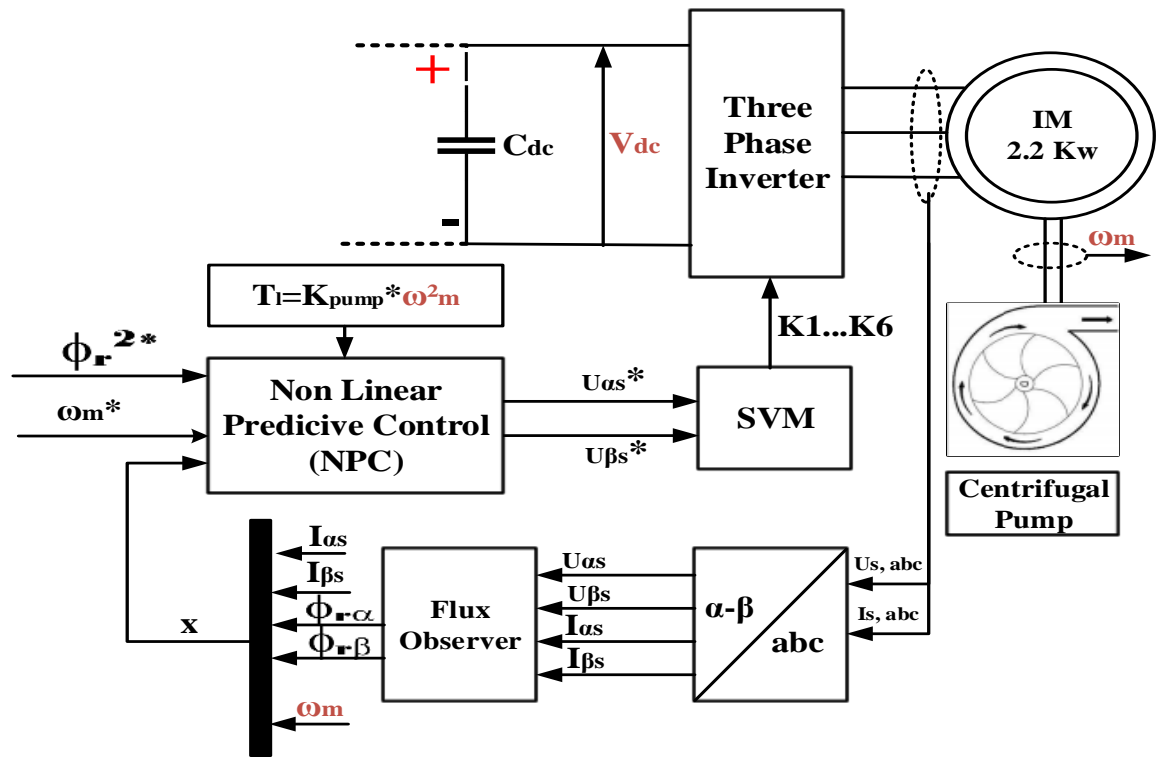

Figure 4. Non-linear predictive control of induction motor

\section{SIMULATION RESULTS AND ANALYSIS}

The hybrid pumping system has been tested in MATLAB / SimulinkTM software. The principal data of the hybrid pumping system are listed in Table 2. Figure 5 (a) shows that linear and sudden irradiances are applied to the system, and the temperature is fixed at $25^{\circ} \mathrm{C}$ value due to its little effect on power variation. Figure 5 (b) describes the evolution of PV voltage, the controller based on DISCM-MPPT tracks fastly the reference voltage $\mathrm{V}_{\mathrm{pv}}{ }^{*}$ provided by $\mathrm{P} \& \mathrm{O}$ algorithm. In addition, a zoomed view on the PV voltage curve illustrates that the voltage fluctuations are small when the MPP is reached. In order to make a fair comparison possible, the designed DISMC-MPPT is compared with both the conventional SMC-MPPT and the ISMC-MPPT under the same operating conditions of the system. Figure 5 (c) and Table 1 clearly show the improvement of the extracted power. From simulation data, it can be observed that the conventional SMCMPPT presents the highest power fluctuations, the slower tracking speed and the largest steady-state error. The ISMC-MPPT increases the tracking speed, but the amplitude of power oscillation is not reduced significantly. In contrast, the DISM-MPPT reduces the amplitude of power oscillation and improves the other performances in comparison with ISMC-MPPT.

Table 1. Comparison of the MPPT properties in terms of power oscillations and tracking speed during sudden change of irradiance

\begin{tabular}{|c|c|c|c|c|c|c|}
\hline \multicolumn{7}{|c|}{$\begin{array}{c}\text { Irradiance }\left(\mathrm{W} / \mathrm{m}^{2}\right) \\
600400200300500700\end{array}$} \\
\hline $\begin{array}{c}\text { MPPT } \\
\text { Technique }\end{array}$ & $\begin{array}{l}\text { Track. Power } \\
\text { speed Oscill. } \\
\quad(\mathrm{ms})(\mathrm{W})\end{array}$ & $\begin{array}{l}\text { Track. Power } \\
\text { speed Oscill. } \\
\quad(\mathrm{ms})(\mathrm{W})\end{array}$ & $\begin{array}{l}\text { Track. Power } \\
\text { speed Oscill. } \\
\quad(\mathrm{ms})(\mathrm{W})\end{array}$ & $\begin{array}{l}\text { Track. Power } \\
\text { speed Oscill. } \\
\quad(\mathrm{ms})(\mathrm{W})\end{array}$ & $\begin{array}{l}\text { Track. Power } \\
\text { speed Oscill. } \\
\quad(\mathrm{ms})(\mathrm{W})\end{array}$ & $\begin{array}{l}\text { Track. Power } \\
\text { speed Oscill. } \\
\quad(\mathrm{ms})(\mathrm{W})\end{array}$ \\
\hline SMC & 4000.8 & 20.3 & -0.09 & -0.2 & 20.9 & 20.8 \\
\hline ISMC & 690.6 & 1.20 .3 & -0.07 & -0.16 & 1.850 .9 & 1.80 .8 \\
\hline DISMC & 690.5 & 10.2 & -0.05 & -0.1 & 1.50 .3 & 1.50 .6 \\
\hline
\end{tabular}

On the other side, the sliding mode control scheme for the bidirectional converter is compared with the conventional PI control scheme. Figures 6 (a) presents the regulated DC-link voltage with both control strategies. For the PI-based controller, it can be seen that the DC-link voltage moves away from its reference 
when the bidirectional converter switches from one mode (charging/discharging) to another. On the other hand, the DC-link voltage is accurately regulated with the sliding mode controllers, in this case, the system presents an insignificant drop of voltage and short setting time when the operating mode changes. Furthermore, the voltage ripples are reduced with the proposed controller. The state of charge (SOC) shown in Figure 6 (b) reflects the battery's charging/discharging modes. The SOC increases when the battery is charging and vice versa. Figure $6(\mathrm{c})$ shows that the inductor $\mathrm{L}_{\mathrm{B}}$ operates in $\mathrm{CCM}$ mode, the battery receives the current from the DC-bus during charging ( $\mathrm{i}_{\mathrm{LB}}$ negative) and delivers the current to DC-bus for the time of discharge (i $i_{\text {LB }}$ positive).

It can be observed from Figure 7 (a) that the non-linear predictive controller tracks the reference speed with a very fast dynamic. The electromagnetic torque curve presents reduced ripples because the curves of stator currents are quite close to the sinusoid form, which is depicted in Figure 7 (b) and Figure 7 (c). Figure 7 (d) shows that the decoupling between the flux and the torque is achieved accurately because the flux stays close to its reference. Since the NPC controller tracks the reference speed with high performance, the centrifugal pump parameters (flowrate, hydraulic power) are improved. Figure 7 (e) and Figure 7 (f) illustrate that these parameters follow exactly their references.

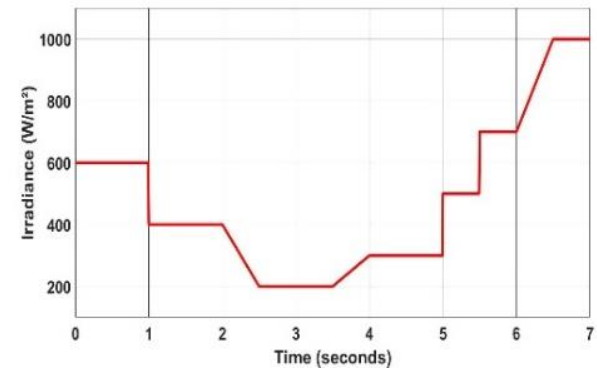

(a)

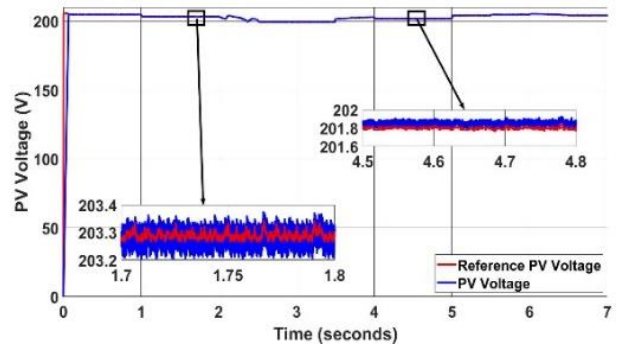

(b)

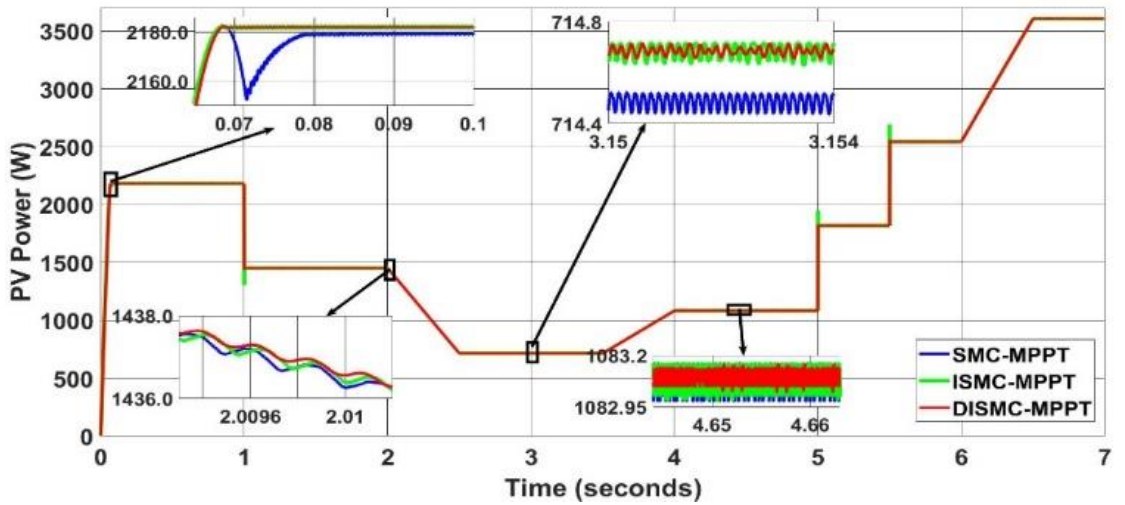

(c)

Figure 5. Simulation results of the PV array parameters under linear and sudden irradiances. (a) Irradiance, (b) PV voltage, (c) The extracted PV power for different methods

Table 2. Hybrid water pumping system parameters

\begin{tabular}{ccc}
\hline & Parameter & Value \\
\hline \multirow{2}{*}{ PV array } & Current at maximum power $\left(\mathrm{I}_{\mathrm{mp}}\right)$ & $17.68 \mathrm{~A}$ \\
& Voltage at maximum power $\left(\mathrm{V}_{\mathrm{mp}}\right)$ & $204 \mathrm{~V}$ \\
& Maximum power $\left(\mathrm{P}_{\mathrm{m}}\right)$ at $\mathrm{STC}$ & $3606.72 \mathrm{~W}$ \\
& Rated power $\left(\mathrm{P}_{\mathrm{m}}\right)$ & $2200 \mathrm{~W}$ \\
& Rated speed $\left(\omega_{\mathrm{r}}\right)$ & $1430 \mathrm{rpm}$ \\
Induction Motor Drive & Rated frequency $(\mathrm{f})$ & $50 \mathrm{~Hz}$ \\
& Nominal voltage $(\mathrm{L}-\mathrm{L})$ & $230 \mathrm{~V}$ \\
& Rated flux $\left(\phi_{\mathrm{r}}\right)$ & $0.6 \mathrm{~Wb}$ \\
Centrifugal Pump & Rated pumping flow $\left(\mathrm{Q}_{\mathrm{r}}\right)$ & $10 \mathrm{~m}^{3} / \mathrm{h}$ \\
& Rated pumping head $\left(\mathrm{H}_{\mathrm{r}}\right)$ & $50 \mathrm{~m}$ \\
Battery Pack & Pump constant $\left(\mathrm{K}_{\text {pump }}\right)$ & $6.55 \times 10^{-4} \mathrm{~W} /(\mathrm{r} / \mathrm{s})^{3}$ \\
\hline
\end{tabular}

Robust non-linear control of a hybrid water pumping system based on induction motor (Zakaria Massaq) 

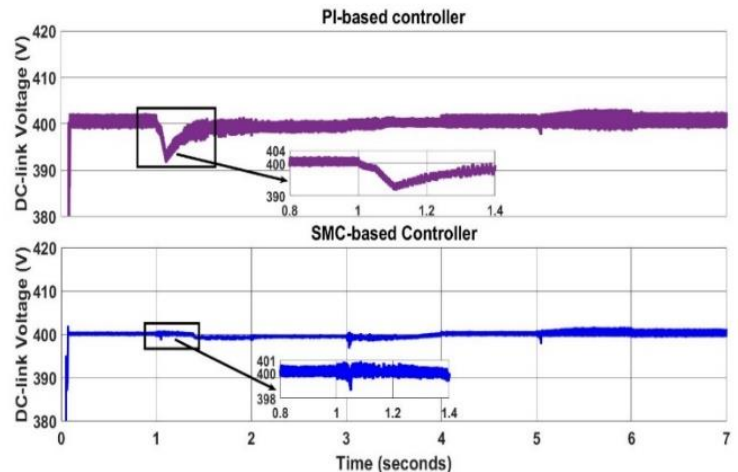

(a)

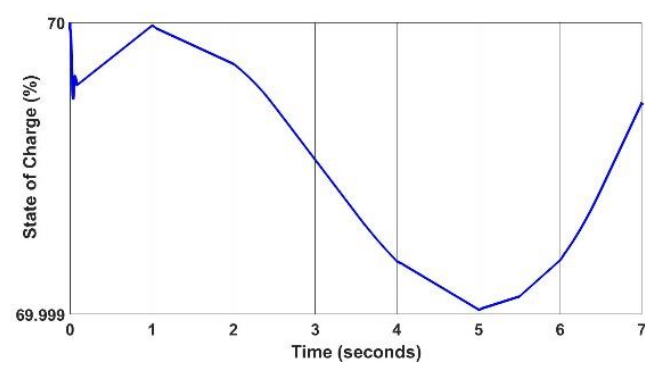

(b)

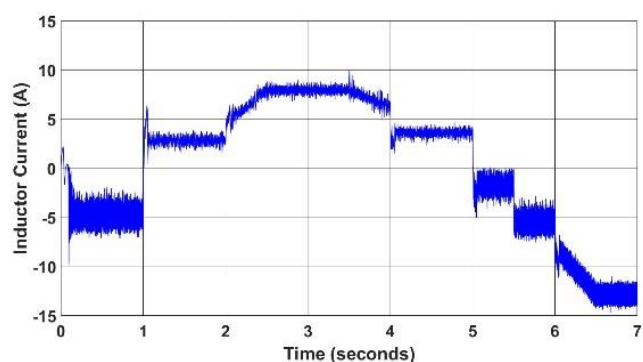

(c)

Figure 6. Simulation results of battery parameters under different load variations.

(a) DC-link voltage for both PI and SMC methods, (b) state of charge, (c) the inductor current $\mathrm{i}_{\mathrm{LB}}$

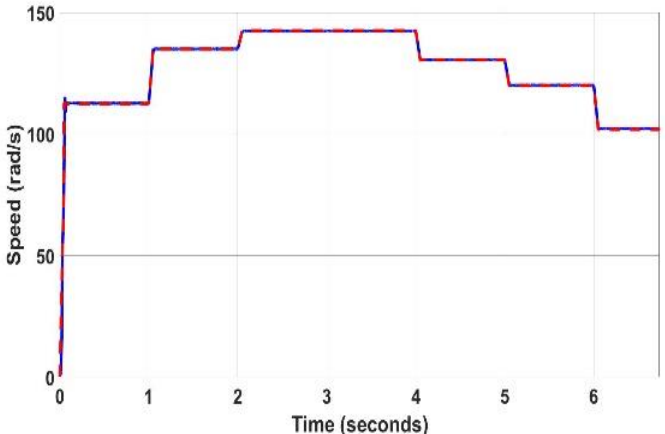

(a)

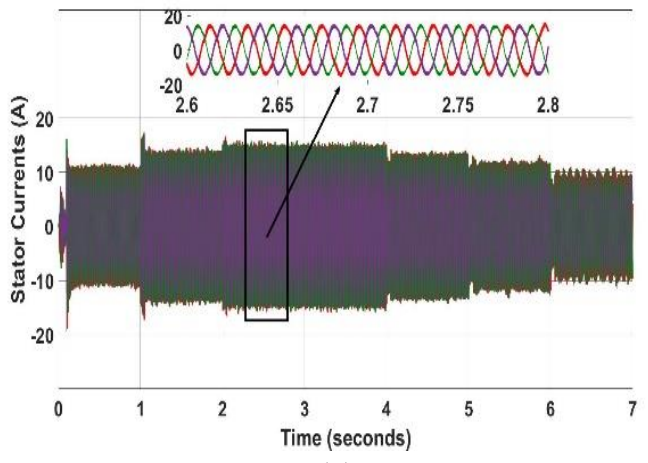

(c)

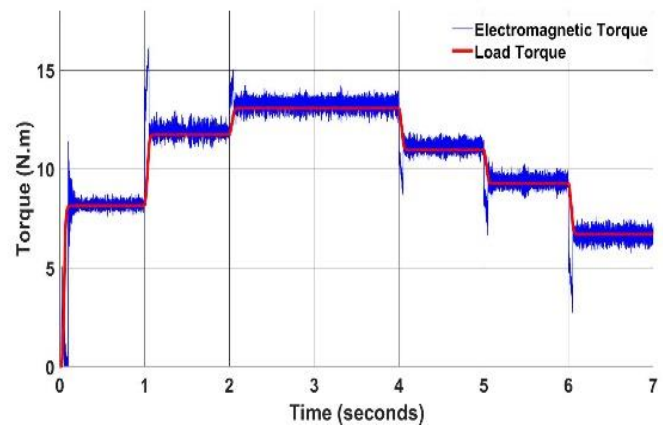

(b)

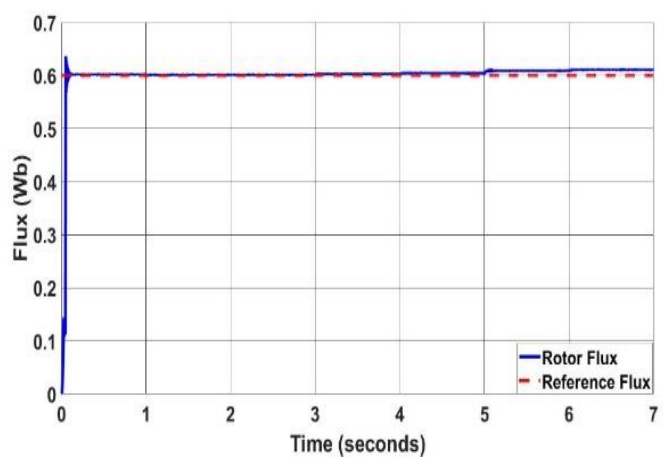

(d) 


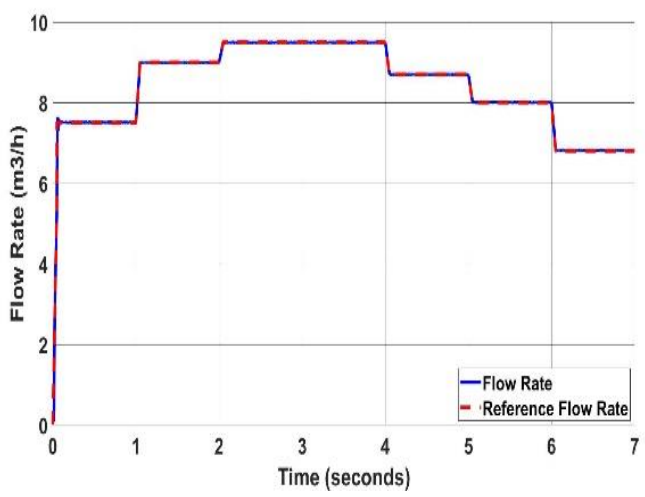

(e)

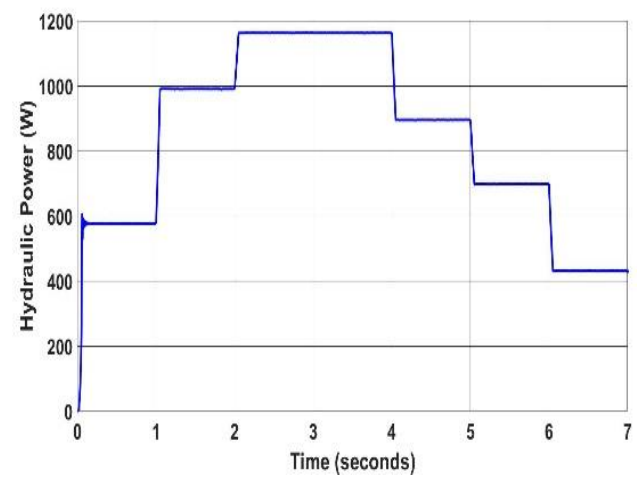

(f)

Figure 7. Simulation results of the motor-pump parameters

(a) rotor speed, (b) electromagnetic torque, (c) stator currents, (d) rotor flux, (e) pump flowrate,

(f) hydraulic power

\section{CONCLUSION}

A robust control scheme of a hybrid water pumping system based on an induction motor was presented in this paper. First, a cascaded controller based on P\&O and the indirect double integral SMC is designed to track the MPP. Seconde, the integral sliding mode control theory has been used to control the bidirectional buck-boost converter. The third stage of the system consists of a three-phase inverter which controls the speed and torque of an induction motor with the non-linear predictive control technique. Analyzing simulation results, it is found that the DISMC-MPPT tracks the MPP with better performances than both SMC-MPPT and ISMC-MPPT methods. The bidirectional converter controlled with the conventional PI controller is not able to preserve the desired response. However, the control scheme based on ISMC theory showed high robustness and operated properly in different irradiances and speeds. Moreover, the NPC exhibited high tracking performances of the speed, fast torque response and fewer ripples in the torque. Since the IM is controlled with high performances, the pump parameters (hydraulic power, flowrate) are improved.

\section{REFERENCES}

[1] N. Chatrenour, H. Razmi and H. Doagou-Mojarrad, "Improved double integral sliding mode MPPT controllerbased parameter estimation for a stand-alone photovoltaic system," Energy Conversion and Management, vol. 139, pp. 97-109, May 2017.

[2] R. Pradhan and B. Subudhi, "A new digital double integral sliding mode maximum power point tracker for photovoltaic power generation application," in 2012 IEEE Third International Conference on Sustainable Energy Technologies (ICSET), 2012, pp. 183-188.

[3] A. Kihal, F. Krim, B. Talbi, A. Laib, and A. Sahli, "A Robust Control of Two-Stage Grid-Tied PV Systems Employing Integral Sliding Mode Theory,” Energies, vol. 11, no. 10, p. 2791, Oct. 2018.

[4] B. Subudhi and R. Pradhan, "Adaptive double-integral-sliding-mode-maximum-power-point tracker for a photovoltaic system," The Journal of Engineering, vol. 2015, no. 10, pp. 305-317, Oct. 2015.

[5] Siew-Chong Tan, Y. M. Lai, and C. K. Tse, "Indirect Sliding Mode Control of Power Converters Via Double Integral Sliding Surface," IEEE Trans. Power Electron., vol. 23, no. 2, pp. 600-611, Mar. 2008.

[6] S.-C. Tan, Y.-M. Lai, and C.-K. Tse, "Sliding Mode Control of Switching Power Converters: Techniques and Implementation," CRC press, p. 301, 2018.

[7] D. Ravi, B. Mallikarjuna Reddy, S. S.L, and P. Samuel, "Bidirectional de to dc Converters: An Overview of Various Topologies, Switching Schemes and Control Techniques," IJET, vol. 7, no. 4.5, p. 360, Sep. 2018.

[8] Zhiling Liao and Xinbo Ruan, "Control strategy of bi-directional DC/DC converter for a novel stand-alone photovoltaic power system," in 2008 IEEE Vehicle Power and Propulsion Conference, Harbin, Hei Longjiang, China, 2008, pp. 1-6.

[9] A. Etxeberria, I. Vechiu, H. Camblong, and J.-M. Vinassa, "Comparison of Sliding Mode and PI Control of a Hybrid Energy Storage System in a Microgrid Application,” Energy Procedia, vol. 12, pp. 966-974, 2011.

[10] C. S. Purohit, G. M, P. Sanjeevikumar, P. K. Maroti, S. Swami, and V. K. Ramachandaramurthy, "Performance analysis of DC/DC bidirectional converter with sliding mode and pi controller," International Journal of Power Electronics and Drive Systems (IJPEDS), vol. 10, no. 1, pp. 357-365, Mar. 2019.

[11] Rahman, Sharjil, Aidil Azwin Zainal Abidin, "A Review on Induction Motor Speed Control Methods." International Journal of Core Engineering \& Management (IJCEM), no. 5 vol. 3, 2016. 
[12] Z. Massaq, A. Abounada, G. Chbirik, M. Ramzi, and A. Brahmi, "Double Stage Solar PV Array Fed Sensorless Vector Controlled Induction Motor for Irrigational Purpose," in 2019 7th (IRSEC), Nov. 2019, pp. 1-6.

[13] V. T. Ha, N. T. Lam, V. T. Ha, and V. Q. Vinh, "Advanced control structures for induction motors with ideal current loop response using field-oriented control," International Journal of Power Electronics and Drive Systems (IJPEDS), vol. 10, no. 4, pp. 1758-1771, Dec. 2019.

[14] R. Pothuraju, T. Ramesh, and Jaipal, "Solar Power Based Two Level Inverter Fed DTFC-SVM of a Sensorless IM Drive," in 2018 2nd International Conference on Trends in Electronics and Informatics (ICOEI), Tirunelveli, 2018, pp. 1039-1045.

[15] A. Merabet, "Nonlinear Model Predictive Control for Induction Motor Drive," in Frontiers of Model Predictive Control, T. Zheng, Ed. InTech, 2012.

[16] D. Abdelghani and A. Boumediène, "Direct Torque Control of Two Induction Motors Using the Nine-Switch Inverter," International Journal of Power Electronics and Drive Systems (IJPEDS), vol. 9, no. 4, pp. 1552-1564, Dec. 2018.

[17] C. Laoufi, Z. Sadoune, A. Abbou, and M. Akherraz, "New model of electric traction drive based sliding mode controller in field-oriented control of induction motor fed by multilevel inverter," International Journal of Power Electronics and Drive Systems (IJPEDS), vol. 11, no. 1, pp. 242-250, Mar. 2020.

[18] R. Hedjar, R. Toumi, P. Boucher, and D. Dumur, "Cascaded Nonlinear Predictive Control of Induction Motor," European Journal of Control, vol. 10, no. 1, pp. 65-80, Jan. 2004.

[19] J. J. Gribble, D. J. Ballance, P. J. Gawthrop, W.-H. Chen, and J. O'Reilly, "Nonlinear PID Predictive Controller," IEE Proceedings - Control Theory and Applications, vol. 146, no. 6, pp. 603-611, Nov. 1999.

[20] X. Zhu and Z. Liao, "Energy management for stand-alone PV system," in 2009 ISECS International Colloquium on Computing, Communication, Control, and Management, Sanya, China, 2009, pp. 311-314.

[21] A. Moubarak, G. El-Saady, and E.-N. A. Ibrahim, "Battery energy storage for variable speed photovoltaic water pumping system," engrXiv, preprint, Jan. 2019.

[22] S.-C. Tan, Y. M. Lai, C. K. Tse, and M. K. H. Cheung, "A Fixed-Frequency Pulsewidth Modulation Based QuasiSliding-Mode Controller for Buck Converters," IEEE Trans. Power Electron., vol. 20, no. 6, pp. 1379-1392, Nov. 2005.

[23] T. Dridi, N. Aouani, and A. Mami, "V/f controlled photovoltaic pumping system under LPV model," in 2017 International Conference on Control, Automation and Diagnosis (ICCAD), Hammamet, Tunisia, 2017, pp. 516521.

[24] M. V. Kumar and U. Salma, "Double Integral Sliding Mode Control Approach for a Three-Phase Grid -Tied Photovoltaic Systems," p. 18.

[25] S. Serna-Garcés, D. Gonzalez Montoya, and C. Ramos-Paja, "Sliding-Mode Control of a Charger/Discharger DC/DC Converter for DC-Bus Regulation in Renewable Power Systems," Energies, vol. 9, no. 4, p. 245, Mar. 2016.

[26] R. Hedjar, R. T. P. Boucher, and D. Dumur, "Cascaded Nonlinear Predictive Control of Induction Motor," European Journal of control, Vol. 10, no. 1, pp.65-80, 2004. 